\title{
Problems and Prospects of Nanometer Transparent Infrared Thermal Insulation Glass
}

\author{
Nan Zhang ${ }^{1,2,3, *}$, M engyuan $\mathrm{Xu}^{1,3}$, and Ning $\mathrm{Li}^{2}$ \\ ${ }^{1}$ Guangzhou Architectural Science Research Institute New Technology Development Center Co., Ltd \\ ${ }^{2}$ South China University of Technology \\ ${ }^{3}$ Guangzhou Institute of Building Science Co., Ltd
}

\begin{abstract}
The existing building energy-saving reconstruction has a large area in our country. If the performance indexes such as the shading coefficient, visible light transmittance and hardness of the coating heat-insulating glass are in the condition of reaching the specification, and it can meet the needs of energy conservation and reform in building, it is a suitable technology for economic application.
\end{abstract}

\section{Preface}

In current design of building energy conservation, improving the performance of building envelope, the efficiency of heating air conditioning system and lighting system are all effective ways to improve building energy-saving efficiency. In building envelope, the thermal performance of glass has always been the biggest factor affecting building energy consumption and human comfort. The heat of solar radiation entering the room through the window is the main reason for the overheating of indoor temperature in the summer. Therefore, it is an effective way to reduce building energy consumption by reducing solar radiation into the room and improving the heat insulation performance of window glass.

Due to relatively large heat transfer coefficient and poor heat insulation effect, single layer glass, as component of building envelope structure, will generally leads to large energy loss. In particular, when the temperature difference between the interior and exterior is large, $20 \%-30 \%$ energy of the air-conditioning load will be lose through the glass. In order to improve the thermal insulation performance of glass and reduce building energy consumption, many kinds of energy-saving glass have appeared on the market, such as film glass, coated glass (low-e glass)and so on . It improves the insulation performance of lass and improves the energy-saving level of the building at great extent, but the cost of the energy saving glass, such as the film glass and the coated glass is high, the technology is more complex and technical difficulty is high. In the process of film coating and glass production, there are not only a lot of energy consumption,but also a large amount of waste, such as smoke, industrial waste-water, sulfur dioxide, nitrogen oxide and other wastes, which will cause a series of environmental issues.

\footnotetext{
* Corresponding author: Nan Zhang: 563965688 @qq.com
}

\section{The advantages of nanometer transparent Infrared Insulated Glass Coating}

Nanometer transparent infrared thermal insulation glass coating is a new type of glass insulation product that has high visible light transmittance and low shading coefficient. It is commonly used in energy saving renovation of new buildings and existing buildings because of its simple and environmentally friendly production technology, better thermal insulation effect and lower price. In the preparation of glass insulation coatings, ATO (Antimony Doped Tin Oxide) is used to Antimony oxide Nanometer insulation materials.

ATO powder is a kind of good conductive oxide with good photothermal properties. It is widely used in some optoelectronic components, thermal barrier, thermal reflection and other new materials. As a kind of material with better transmittance and heat insulation properties, ATO is also used in heat insulation slurry, and the research on ATO coating heat insulation slurry and its related glass products is also a hot spot and focus in the field of building energy saving glass at home and abroad [1-3].

\section{Domestic research status}

Through the analysis of the hardness, adhesion, visible light transmittance and shading coefficient of the building coating insulation glass produced by domestic universities, scientific research institutes and enterprises and other units. we found that the technology is more advanced and representative have he following units.

\subsection{Research status of universities and research institutes}


Professor Meng Qinglin from South China University of Technology has studied building glass insulation coating and made ATO waterborne polyurethane Nanometer-insulation coating. The sun shading coefficient of $6 \mathrm{~mm}$ coated glass was less than 0.67 , the visible light transmittance was greater than $63 \%$, and the hardness was $2-3 \mathrm{H}$. When the aging time is 240 hours, the surface of coated glass has no obvious change. At the same time, the coating meets the requirements of environmental protection, and has applied for the national invention patent. The preparation of waterborne polyurethane for film forming agent was studied by Zhang Fuqiang and Li Xue from Hebei University of Technology. The result is that the hardness of waterborne polyurethane is B. At the same time, they also studied the effect of epoxy acrylate and isocyanate curing agent on photothermal index of waterborne polyammonia coatings. It was found the film hardness of the coating glass was $2 \mathrm{H}$, and the thermal insulation temperature difference was $9{ }^{\circ} \mathrm{C}$ when the infrared lamp was used as the heat source to irradiate the coated glass.

\subsection{Enterprise, company research and product status}

Through the company's research, it was found that the glass thermal insulation coating produced by Lanzhou Weishile Energy-saving Materials company has a good thermal insulation effect. The waterborne coating has low hardness and adhesion, and the hardness range is 1-3H. Shanghai Huzheng Nanometer Technology Co., Ltd. developed the infrared insulation barrier of glass heat insulation coating can reach $90 \%$, visible light transmittance of more than $80 \%$, the surface drying time is 15 minutes, the water layer hardness is $1 \mathrm{H}-2 \mathrm{H}$, the hardness of solvent-based film layer is above $3 \mathrm{H}$ and the low temperature storage period is more than 1.5 years. Yantai Jialong Nanometer Industry Co., Ltd. produces a heat insulating coating for architectural glass. After the coating is applied, the visible light transmittance of the glass is $60 \%-85 \%$, the infrared ray blocking rate is over $80 \%$, the waterborne material hardness is $1 \mathrm{H}-3 \mathrm{H}$, and the hardness of the solvent type material was above $3 \mathrm{H}$. The glass coating produced by Shenzhen De hou Technology Co., Ltd. has good spectral selectivity and stability, crystal clear coating, high visible light transmittance, strong UV shielding ability, solvent-based film hardness of more than $3 \mathrm{H}$, and adhesion of 0 , the infrared barrier rate is more than $80 \%$, and the visible light penetration rate is more than $85 \%$ [4-7].

In addition, Chen Jialin from Shanghai Hui state special coating Co., Ltd., Xiamen Jun Hui Technology Co., Ltd., Changsha science star Nanometer engineering Technology Co., Ltd., Zhuhai thermal shield energy saving Technology Co., Ltd. and other enterprises or units have carried out research and development or promotion of Nanometer transparent insulation coatings.

In the standard formulation, China has promulgated and implemented $《 \mathrm{JG} / \mathrm{T} 338-2011$ building glass insulation coatings $》$ and $\langle\mathrm{GB} / \mathrm{T} 29501-2013$ insulation coating glass $》$.The definition of thermal insulation coatings for building glass, hardness index, limit of harmful substances and others indexes have been standardized.

\section{Overseas Research Status}

In the process of production and research of foreign glass insulation coatings, there are some characteristics of material formula and core technology to a certain extent, such as high secrecy to the outside world, high price of coating materials and tools.

\subsection{Research and Product Status o Enterprises and Colleges}

Japan's Cage Co. produces 2 kinds of coatings, IR (anti infrared) thermal insulation glass coating and IRUV (anti infrared and ultraviolet) coating. The coating not only has better indexes in hardness, visible light transmittance, infrared UV barrier rate, energy saving effect, inhibition of condensation rate, hardening time and so on, but also has transparent and clear film, without concave and convex, and does not appear connection. SealProtec CleanSun type sunscreen glass coating produced by German Mandich Sales Co., Ltd is a light blue liquid coating that can block $86 \%$ of infrared rays, and the visible light transmittance can reach $80 \%$. It also has stronger attribute in durability and hardness. The coating material is expensive, which price at almost 2800 yuan RMB per bottle (about $800-1200 \mathrm{ml}$ ).

The surface hardness of glass insulation manufactured by American RPM International Group coating is $2 \mathrm{H}$, the adhesion level is 0 , coating thickness is $8-10$ um, the transmission in visible region is over $85 \%$ and near infrared ray blocking rate is over $80 \%$. The transparent and insulated water-based coatings produced by HDMG company in Singapore have the UV radiation shielding rate of $95 \%$, the infrared suppression rate of $92 \%$, the visible light transmittance of $72 \%$, so that the indoor temperature can be reduced by 5-7 degrees centigrade in the summer and increased by 3-5 degrees centigrade in the winter. The curing time of the material is about 20 minutes at room temperature, with good adhesion, and its service life is $8-10$ years [8-11].

\subsection{Existing Relevant Standards}

In terms of standard setting, France, Germany, Greece, Britain and other countries have implemented equal standards, include 《Glass in building Coated glass Part 1, Definitions and classification; Part 1, Definitions and classification; Part 2, Test methods for durability of A, B and Coatings; Part 3, Test methods for durability of $\mathrm{C}$ and D coatings; Part 4, Factory production control and evaluation of conformity $》$. The United States has implemented standard terms for ASTMD 16-2007 coatings, related coatings, materials and applications, standard specifications for external solar radiation coating for ASTM C 1483-2004 buildings, standard test methods for adhesion or bond strength of ASTM C 
633-2001 thermal spraying layers.

\section{Summary and main problems of research in domestic and foreign}

Through the research on the existing documents, papers, reports, patents and standards of architectural glass insulation coatings in domestic and foreign, it is shown that building glass thermal insulation coatings and film insulation glass are widely recognized because of its low cost, good near infrared barrier rate and heat insulation performance.

The domestic and foreign enterprises, companies, universities and scientific research institutes have carried out a series of research and Exploration on the building glass Nanometer thermal insulation coatings and film insulation glass, but there are three problems in the following aspects: (1) Because the dispersing method of slurry is single, the stability time of slurry is mostly about 1.5 years, resulting in poor dispersion stability and short storage time.(2) The lack of research on the infrared transmittance of $1000 \mathrm{~nm}$ band leads to the difficulty of improving the infrared barrier index or the deterioration of hardness, adhesion, UV resistance and anti-aging performance after the enhancement of the infrared barrier index. Most of the maximum aging resistance experiments mentioned are 240-360 hours.(3) Based on this research, the light and thermal parameters of the insulating glass with engineering significance are not quantified, especially the experimental verification which is fitted to the engineering practice.

\section{6 conclusion}

The area of energy-saving reconstruction of existing buildings in our country is enormous and the task is arduous. Building windows and doors energy-saving transformation technology need to be in accordance with the real conditions of our country. When the performance index of the coating film insulation glass shading coefficient, visible light transmittance and hardness reach the requirements of the specification requirements, they can meet the requirements of building energy-saving transformation. It is an economically applicable technology, and is particularly suitable for the energy conservation of existing buildings. In the process of localization, the application of architectural glass insulation coating and coated insulating glass can create greater economic, social and environmental value.

\section{Acknowledgment}

This research is supported by National Natural Science Foundation of China (NO.51608205), Pearl River Nova Program of Guangzhou and Science Development Foundation of Guangzhou Institute of Building (201710010157).

\section{References}

1. F F.Bai, Y.He,P.He. One - step synthesis of mono-dispersed antimony - doped tin oxide suspension, Mate-rials Letters,(2006).

2. S G.Mei,W J.Ma,G L.Zhang,Transparent ATO/epoxy nanocomposite coating with excellent thermal insulation property,Micro\& Nano Letters, 7(2012).

3. X Y.Zhang, L H.Ying, X Y. Liu, Study on the nanoATO based transparent heat - insulation silicone coating, Paint \& Coatings Industry, 42(2012).

4. Lina.Sun,Hong.Gao,Shengyang.Liu,Research progress of energy saving glass, Energy conservation,1 (2011).

5. HJ.Tan, JZ.Zhang, Chunyue.Pan,Summary of building energy efficiency materials. Building energy efficiency, 37(2009).

6. YF.Leng, Hui.Zhao, Yuan.Zhang, Research on energy saving of residential buildings in hot summer and cold winter zone 65\%,Building energy efficiency,38(2010).

7. Wenhong .Yu , Zhao. Yang, Low radiation glass, Energy saving, 2(2005).

8. J. Qu,JR. Song, J. Qin, Transparent thermal insula-tion coatings for energy efficient glass windows and curtainwalls, Energy and Buildings, 77(2014).

9. M. Koebel, Y.Nadargi, C.Jimenez, Transparent,conducting ATO thin films by epoxide-initiated solgel chemistry: A highly versatile route to mixed-metal oxide films. ACS Applied Materials and Interfaces,4(2012).

10. Thermal calculation code for glass curtain walls of building doors and windows, JGJ/T151-2008.

11. Thermal insulation coatings for building glass, JG/T 338-2011. 